\title{
Evaluation of the Stress Tolerance of Salmonella with Different Antibiotic Resistance Profiles
}

\author{
Xingning Xiao, ${ }^{1}$ Biao Tang, ${ }^{1}$ Siyi Liu, ${ }^{2}$ Yujuan Suo, ${ }^{3}$ Hua Yang, ${ }^{1}$ and Wen Wang $\mathbb{D}^{1}$ \\ ${ }^{1}$ State Key Laboratory for Managing Biotic and Chemical Threats to the Quality and Safety of Agro-Products, MOA Laboratory of \\ Quality \& Safety Risk Assessment for Agro-Products (Hangzhou), Institute of Agro-Product Safety and Nutrition, \\ Zhejiang Academy of Agricultural Sciences, Hangzhou 310021, China \\ ${ }^{2}$ College of Food Science and Engineering, Hainan University, Haikou 570228, China \\ ${ }^{3}$ Institute for Agri-Food Standards and Testing Technology, Shanghai Academy of Agricultural Science, Shanghai 201403, China
}

Correspondence should be addressed to Wen Wang; ww_hi1018@163.com

Received 22 June 2021; Revised 9 August 2021; Accepted 27 August 2021; Published 15 September 2021

Academic Editor: M. C D Vanetti

Copyright (C) 2021 Xingning Xiao et al. This is an open access article distributed under the Creative Commons Attribution License, which permits unrestricted use, distribution, and reproduction in any medium, provided the original work is properly cited.

\begin{abstract}
Disease caused by antibiotic-resistant Salmonella is a serious clinical problem that poses a great threat to public health. The present study is aimed at assessing differences in bacterial kinetics with different antibiotic resistance profiles under environmental stress and at developing microbial tolerance models in lettuce during storage from 4 to $36^{\circ} \mathrm{C}$. The drugresistance phenotypes of 10 Salmonella Typhimurium (S. Typhimurium) isolates were examined using the broth microdilution method. The results of $10 \mathrm{~S}$. Typhimurium isolates in the suspensions showed that a slow trend towards reduction of drugsensitive (DS) isolates in relation to the others though without statistical difference. Compared to DS S. Typhimurium SA62, greater bacterial reduction was observed in multidrug-resistant (MDR) S. Typhimurium HZC3 during lettuce storage at $4^{\circ} \mathrm{C}$ $(P<0.05)$. It was likely that a cross-response between antibiotic resistance and food-associated stress tolerance. The greater growth in lettuce at $12^{\circ} \mathrm{C}$ was observed for DS S. Typhimurium SA62 compared to MDR S. Typhimurium HZC3 and was even statistically different $(P<0.05)$, while no significant difference was observed for bacterial growth between MDR $S$. Typhimurium HZC3 and DS S. Typhimurium SA62 strains in lettuce storage from 16 to $36^{\circ} \mathrm{C}(P>0.05)$. The goodness-of-fit indices indicated the Log-linear primary model provided a satisfactory fit to describe the MDR $S$. Typhimurium HZC3 and DS $S$. Typhimurium SA62 survival at $4^{\circ} \mathrm{C}$. A square root secondary model could be used to describe the effect of temperature (12, 16,28 , and $\left.36^{\circ} \mathrm{C}\right)$ on the growth rates of $S$. Typhimurium HZC3 $\left(\right.$ adj $-R^{2}=0.91$, RMSE $\left.=0.06\right)$ and $S$. Typhimurium SA62 $\left(\right.$ adj $\left.-R^{2}=0.99, \mathrm{RMSE}=0.01\right)$ derived from the Huang primary model. It was necessary to pay attention to the tolerance of antibiotic resistant bacteria under environmental stress, and the generated models could provide parts of the input data for microbial risk assessment of Salmonella with different antibiotic resistance profile in lettuce.
\end{abstract}

\section{Introduction}

Salmonella is a zoonotic bacterium and is among the most important pathogens causing bacterial foodborne diseases. About $70-80 \%$ of foodborne disease outbreaks are caused by Salmonella in China [1]. In 2016, a total of two Salmonella outbreaks in Australia have been attributed to fresh produce and Salmonella Anatum outbreak (144 cases) linked to prepackage lettuce and Salmonella Hvittingfoss (97 cases) linked to rock melons [2]. Salmonella contamination occurs during both production and preparation phases by exposure to contaminated water, soil, insect, or animal fecal matter and through cross-contamination [3]. Animal manure used as fertilizers is a potential source of contamination of raw vegetables [4]. Consumers have also been known to prepare ready-to-eat salad fruits and vegetables with utensils previously used to prepare raw chicken for cooking. This has led to cross-contamination, growth, and exposure to and illness from Salmonella of chicken origin [5]. A systematic review of Salmonella contamination of lettuce indicated that 
Salmonella prevalence in lettuce was $2.1,1.0$, and $16.9 \%$ for farm, industry, and retail markets, respectively [3]. These pose a serious threat to the public health.

Over the past decades, emerging antibiotic resistance has become a global concern, and although procedures have been adopted to avoid resistance spread, antibioticresistant bacterial strains among food isolates are still observed [6]. Antibiotic-resistant bacteria, especially zoonotic bacteria such as Salmonella which infect edible animals, can be transmitted to humans via the food chain or through skin contact [7]. Salmonella isolates displaying resistance to clinically important antibiotic agents have increased in China and other countries $[4,8]$. A previous study collected 406 raw vegetable samples from retail markets in 39 Chinese cities, and the prevalence of Salmonella in lettuce, coriander, cucumber, and tomato were $6.0,7.8$, 0.8 , and $1.0 \%$, respectively. In total, 4 (26.7\%) Salmonella isolates with multidrug-resistant (MDR) phenotypes were detected in raw vegetable samples, including two isolates from lettuce and two isolates from coriander [4]. Salmonella isolates in lettuce displayed higher frequency of MDR phenotypes than other types of raw vegetables [4, 9]. Pathogenic bacteria in foods usually experience many stress conditions during food production and processing, which could lead the bacteria into the sublethal injury and viable but nonculturable state. Such conditions can be chlorine or acid chemical treatments or physical stresses, such as cold or heat treatments [10]. Drug-resistant (DR) Staphylococcus aureus (S. aureus) has been found to be more resistant to acid, heat, and osmotic pressure than drug-sensitive (DS) bacteria [10]. The DR Escherichia coli O157:H7 (E. coli O157:H7) was sensitive to cold stress during yogurt and juice storage at $4^{\circ} \mathrm{C}$ [11]. Besides, no significant difference for the tolerance of DS and DR Listeria monocytogenes (L. monocytogenes) to thermal stress was reported [12]. It was necessary to pay attention to the tolerance of antibiotic-resistant bacteria under environmental stress. Concerning growth and survival kinetics of Salmonella with different antibiotic resistance profiles in the suspensions and lettuce, research in this area was still scarce.

Predictive microbiology has been used as an important tool to improve food safety by developing mathematical models to quantitatively predict the growth or survival of microorganisms under prescribed environmental conditions during food processing $[13,14]$. Currently, there exists a wealth of data and models that can be used to predict the changes in the Salmonella in lettuce during storage [15, 16]. For example, Salmonella spp. were inoculated separately in lettuce and stored at 5 to $37^{\circ} \mathrm{C}$, and growth curves were constructed by fitting the data to the Baranyi model [16]. A chicken isolate of Salmonella Newport (S. Newport) has also been used to construct an artificial neural network model in lettuce during storage at temperature of 16 to $40^{\circ} \mathrm{C}$ as well as Salmonella Enterica ( $S$. Enterica) ATCC 13076 in minimally processed lettuce as a function of temperature $[9,15]$. There was evidence that the growth and survival patterns of DR strains were different from their DS counterparts during treatment at different temperatures, while few model that included the growth and survival of
Salmonella with different antibiotic resistance in lettuce [17]. There is a need to incorporate into models on the variability of microbial responses with different antibiotic resistance, which will improve the utility of predictive models for exposure assessment and decrease the variability of the quantitative microbial risk assessment (QMRA) model $[17,18]$.

The objectives of the current study were to (i) assess differences of growth and survival kinetics of isolated strains with different antibiotic resistance profiles to environmental stress and to (ii) construct mathematical models to describe the behaviors of $S$. Typhimurium with different antibiotic resistance profiles in lettuce storage from 4 to $36^{\circ} \mathrm{C}$.

\section{Material and Methods}

2.1. Bacterial Strains and Culture Conditions. Ten strains of S. Typhimurium (SA62, Z62, Z95, Z9, X79, Z27, HZC3, X54, $\mathrm{X} 100$ and $\mathrm{X} 63$ ) isolated from anal swabs in poultry farm in Guangdong province were used in the study. These isolates were stored in brain heart infusion broth (BHI, Becton Dickinson (BD), Franklin Lakes, NJ, USA) containing 20\% glycerol at $-80^{\circ} \mathrm{C}$. Each strain was separately incubated in $\mathrm{BHI}$ at $37^{\circ} \mathrm{C}$ for $24 \mathrm{~h}$ and cultured to approximately $9 \log \mathrm{CFU} / \mathrm{mL}$. Appropriate 10-fold dilutions in sterile phosphate buffered saline (PBS, Sigma, St. Louis, MO, USA) were made and plated on Xylose Lysine Tergitol-4 (XLT4, BD, Franklin Lakes, NJ, USA) agar incubated $37^{\circ} \mathrm{C}$ for $18 \mathrm{~h}$ to determine number of colonies forming units per milliliter in the suspensions.

2.2. Antibiotic Susceptibility Tests. Bacterial suspensions were prepared by suspending 3-5 individual colonies grown at $37^{\circ} \mathrm{C}$ for $18 \mathrm{~h}$ on Trypticase Soy agar (TSA, $\mathrm{BD}$, Franklin Lakes, NJ, USA) into $3 \mathrm{~mL}$ of $0.9 \%$ saline, equivalent to the turbidity of a $0.5 \mathrm{McF}$ arland standard. The 0.5 McFarland inoculum suspensions were further diluted at $1: 100$ in Mueller-Hinton broth $(\mathrm{MH}, \mathrm{BD}$, Franklin Lakes, NJ, USA). Then, the panel of antibiotic agents was reconstituted by adding $200 \mu \mathrm{L} /$ well of the inoculum and incubated at $37^{\circ} \mathrm{C}$ for $18 \mathrm{~h}$. Antibiotic susceptibility testing was performed using the broth microdilution method with the commercial Gram-negative antibiotic panel (Biofosun, Fosun Diagnostics, Shanghai, China) consisting of ampicillin (resistant, AMP $\geq 32$ $\mu \mathrm{g} / \mathrm{mL}$ ), amoxicillin/clavulanate (resistant, $\mathrm{AMC} \geq 32$ $\mu \mathrm{g} / \mathrm{mL}$ ), cefotaxime (resistant, CTX $\geq 4 \mu \mathrm{g} / \mathrm{mL}$ ), meropenem (resistant, $\mathrm{MEM} \geq 4 \mu \mathrm{g} / \mathrm{mL}$ ), amikacin (resistant, $\mathrm{AMK} \geq 64 \mu \mathrm{g} / \mathrm{mL}$ ), $\quad$ gentamicin (resistant, $\mathrm{GEN} \geq 16$ $\mu \mathrm{g} / \mathrm{mL}$ ), colistin (resistant, $\mathrm{CS} \geq 2 \mu \mathrm{g} / \mathrm{mL}$ ), ceftiofur (resistant, $\quad$ CEF $\geq 8 \mu \mathrm{g} / \mathrm{mL}$ ), ciprofloxacin (resistant, CIP $\geq 1$ $\mu \mathrm{g} / \mathrm{mL}$ ), sulfamethoxazole (resistant, $\mathrm{T} / \mathrm{S} \geq 4 / 76 \mu \mathrm{g} / \mathrm{mL}$ ), tetracycline (resistant, TET $\geq 16 \mu \mathrm{g} / \mathrm{mL}$ ), tigecycline (resistant, TIG $\geq 8 \mu \mathrm{g} / \mathrm{mL}$ ), and florfenicol (resistant, FFC $\geq 16$ $\mu \mathrm{g} / \mathrm{mL})$. The breakpoints for each antibiotic agent were set by the Clinical and Laboratory Standards Institute and the European Committee on Antibiotic Susceptibility Testing $[19,20]$. 
2.3. Assessment of Salmonella Stress Tolerance. Each isolate was allowed to achieve a final concentration of approximately $9 \log \mathrm{CFU} / \mathrm{mL}$, as described in Section 2.1. The initial concentrations of suspensions to the environmental stress were selected based on the preliminary test and previous study [21]. To evaluate the effect of low storage temperatures on the tolerance of Salmonella, suspensions containing approximately $3 \log \mathrm{CFU} / \mathrm{mL}$ were stored at 4, 12, 24, and $36^{\circ} \mathrm{C}$. Sampling was carried out at varying time intervals depending on the storage temperature. To assess the heat tolerance of Salmonella, a total of $10 \mathrm{~mL}$ suspensions containing approximately $8 \log \mathrm{CFU} / \mathrm{mL}$ were poured into a glass tube and exposed to hot water at 60 and $75^{\circ} \mathrm{C}$ for $2 \mathrm{~min}$ in a laboratory water bath (TX150, Grant, Royston, UK) equipped with a digital thermometer (34970A, Agilent, Santa Clara, CA, USA) to monitor both temperatures of water and bacterial suspensions. Sodium hypochlorite $(\mathrm{NaClO})$ stock solution containing $56.8 \mathrm{mg} / \mathrm{mL}$ chlorine (Sangon Biotech Co., Ltd., Shanghai, China) was diluted with sterile Milli-Q water (PALL, Buckinghamshire, UK), and the concentration in solution was 100 and $200 \mathrm{mg} / \mathrm{L}$ determined using a Palintest ChlorSense meter (KEMS10DISCN, Gateshead, Tyne and Wear, UK). To examine chlorine tolerance, Salmonella suspensions with initial concentration of approximately $5 \log \mathrm{CFU} / \mathrm{mL}$ were inoculated into $\mathrm{NaClO}$ solution of 100 and $200 \mathrm{mg} / \mathrm{L}$ for $10 \mathrm{~min}$. In the preliminary tests, XLT4 agar was compared with TSA in plate counting, and only less than $0.1 \log \mathrm{CFU} / \mathrm{mL}$ difference was observed, which was not significantly different $(P>0.05)$ as determined by ANOVA. Therefore, the Salmonella were selectively enumerated on XLT4 agar using a spiral plater (WASP 2, Don Whitley Scientific, Shipley, UK). The plates were incubated at $37^{\circ} \mathrm{C}$ for $18 \mathrm{~h}$, and colonies were enumerated using a ProtoCOL 3 automated colony counter (Synbiosis, Cambridge, UK). The viable bacterial populations on samples were expressed as $\mathrm{CFU} / \mathrm{mL}$, and the detection limit was $1.3 \log \mathrm{CFU} / \mathrm{mL}$. Triplicate experiments were performed for each isolate.

\subsection{Evaluation of Salmonella Stress Tolerance in Lettuce} Storage. Lettuce was purchased at supermarket in Hangzhou, China, and these samples were transported to the laboratory using ice bags. Debris and other particles of lettuce leaves were washed with running tap water to reduce natural microbiota load, dried inside a laminar flow safety cabinet, and exposed to UV for $30 \mathrm{~min}$. The intact leaves were cut into $5 \times 5 \mathrm{~cm}$ pieces using a sterile surgical knife and put it into the disinfected plastic plates. These samples were divided into two groups. One group was processed for inspection process, and no Salmonella was initially present on the three pieces of lettuce. The other group was processed for the storage study. The samples were submerged into Salmonella suspensions containing approximately 5 log $\mathrm{CFU} / \mathrm{mL}$ for $10 \mathrm{~min}$ and were dried inside a laminar flow safety cabinet for another $30 \mathrm{~min}$. The initial inoculum level on the lettuce was $3 \pm 0.2 \log \mathrm{CFU} / \mathrm{cm}^{2}$. Inoculated portions of lettuce were stored in stomacher bags at $4,12,16,28$, and $36^{\circ} \mathrm{C}$. Sampling was carried out at varying time intervals depending on the storage temperature. At each time point, three lettuce samples were individually added to sterile stomacher bags (Seward, London, UK) containing $25 \mathrm{~mL}$ buffered peptone water (BPW, BD, Franklin Lakes, NJ, USA) and homogenized for $1 \mathrm{~min}$ in a Model 400 food stomacher (Seward, London, UK). The homogenates were serially 10 -fold diluted in BPW, and a $50 \mu \mathrm{L}$ portion of appropriate dilutions was plated in duplicate onto the XLT4 agar using a spiral plater. The plates were incubated at $37^{\circ} \mathrm{C}$ for $16 \mathrm{~h}$. Colonies on XLT4 agar plates were enumerated by a ProtoCOL 3 automated colony counter. The viable bacterial populations in lettuce samples were expressed as $\mathrm{CFU} / \mathrm{cm}^{2}$, and the detection limit was $1.3 \log \mathrm{CFU} / \mathrm{cm}^{2}$. Each treatment was repeated twice on different days using duplicate plates for each sample.

2.5. Microbial Modeling in Lettuce Storage. The primary model is used to predict the number of bacteria in food at a constant temperature [18]. The growth and survival patterns of Salmonella under different storage temperatures were plotted as the $\log$ of the population size $\left(\log N_{t}\right)$ against time $(t)$ and were analyzed to develop primary models. For the survival curve of Salmonella under $4^{\circ} \mathrm{C}$, a Log-linear model was used. This model assumes a homogeneous bacterial resistance to refrigeration described with a linear relationship between the log of the population density and storage time. It has been frequently used for bacterial survival curve fitting $[22,23]$.

$$
\log N_{t}=\log N_{0}-\frac{t}{D},
$$

where $N_{t}\left(\mathrm{CFU} / \mathrm{cm}^{2}\right)$ is the bacterial population at time $t, N_{0}$ is the initial bacterial population $\left(\mathrm{CFU} / \mathrm{cm}^{2}\right)$, and $D$ is the decimal reduction time (h) at a specific treatment temperature.

Growth curves of Salmonella incubated at 12, 16, 28, and $36^{\circ} \mathrm{C}$ utilized four primary models from (2) to (5) that were chosen to fit the growth data collected from storage experiments. Their performances were compared to determine the model with the best fit.

The Modified Gompertz model (2) has been widely used in bacterial growth modeling studies [22].

$$
\begin{aligned}
\log N_{t}= & \log N_{0}+\log \frac{N_{\max }}{N_{0}} \times \exp \\
& \cdot\left\{-\exp \left[\frac{2.718 \mu_{\max }}{\log \left(N_{\max } / N_{0}\right)} \times \mathrm{m}(\lambda-t)+1\right]\right\} .
\end{aligned}
$$

The Huang model (3) is especially suitable for growth curves with three phases (lag, exponential, and stationary) [24].

$$
\begin{aligned}
\log N_{t}= & \log N_{0}+\log N_{\max }-\log \left(\exp \left(\log N_{0}\right)\right. \\
& \left.+\left(\exp \left(\log N_{0}\right)-\exp \left(\log N_{0}\right) * \exp \left(-\mu_{\max } *(B)\right)\right)\right) \\
B= & t+0.25 * \log \frac{(1+\exp (-4 *(t-\lambda)))}{1+\exp (4 * \lambda)}
\end{aligned}
$$


TABle 1: Antibiotic resistance phenotype of Salmonella isolates.

\begin{tabular}{|c|c|c|c|}
\hline Isolation & Phenotypic antibiotic resistance & Number of resistant antibiotics & Classification \\
\hline SA62 & - & 0 & \multirow{2}{*}{$\mathrm{DS}^{\mathrm{a}}$} \\
\hline Z62 & - & 0 & \\
\hline Z95 & TET & 1 & \multirow{4}{*}{$\mathrm{DR}^{\mathrm{b}}$} \\
\hline Z9 & CIP-FFC & 2 & \\
\hline $\mathrm{X} 79$ & AMC-FFC & 2 & \\
\hline $\mathrm{Z} 27$ & CIP-TET & 2 & \\
\hline X63 & CS-T/S-TET-FFC & 4 & \multirow{4}{*}{$\mathrm{MDR}^{\mathrm{c}}$} \\
\hline HZC3 & AMP-AMC-CIP-TET-FFC & 5 & \\
\hline $\mathrm{X} 54$ & AMP-MEM-GEN-CEF-T/S-TET-FFC & 7 & \\
\hline $\mathrm{X} 100$ & AMP-AMC-CTX-GEN-CIP-T/S-TET-FFC & 8 & \\
\hline
\end{tabular}

${ }^{a}$ DS: bacterial sensitive to all 13 antibiotics, including ampicillin (AMP), amoxicillin/clavulanate (AMC), cefotaxime (CTX), meropenem (MEM), amikacin (AMK), gentamicin (GEN), colistin (CS), ceftiofur (CEF), ciprofloxacin (CIP), sulfamethoxazole (T/S), tetracycline (TET), tigecycline (TIG), and florfenicol (FFC), was DS bacteria. ${ }^{b} \mathrm{DR}$ : bacteria resistant to one or two antibiotics were called DR bacteria. ${ }^{c}$ MDR: multidrug resistance was defined as resistance to at least three antibiotics.

The logistic model has been widely used to describe the growth curve like the sigmoidal type on (4) [25].

$$
\log N_{t}=\log N_{0}+\left(\log N_{\max }-\log N_{0}\right)\left(1+\left(\frac{t}{t_{0}}\right) \wedge \mu_{\max }\right) \text {. }
$$

The Baranyi model assumes that during the lag phase, the specific growth rate depends on the need of each cell to synthesize an intracellular substance referred to as a bottleneck-modeling function on (5) [26].

$$
\begin{aligned}
& \log N_{t}=\log N_{0}+\mu_{\max } A(t)-\ln \left(1+\frac{\exp \left(\mu_{\max } A(t)\right)-1}{\exp \left(\log N_{\max }-\log N_{0}\right)}\right), \\
& A(t)=t+\frac{1}{\mu_{\max }} \ln \left(\exp \left(-\mu_{\max } t\right)+\exp \left(-h_{0}\right)-\exp \left(-\mu_{\max } t-h_{0}\right)\right) .
\end{aligned}
$$

In Equations (2)-(5), $N_{0}, N_{\max }$, and $N_{t}\left(\mathrm{CFU} / \mathrm{cm}^{2}\right)$ represent the initial, maximum, and time $t(\mathrm{~h})$ bacterial populations, respectively, $\lambda$ is the lag time (h), $\mu_{\max }$ is the maximum specific growth rate $\left(\log \mathrm{CFU} / \mathrm{cm}^{2} / \mathrm{h}\right)$, and $h_{0}$ is the physiological state of the microorganism.

The secondary model was used to predict parameters obtained from the primary model with temperature changes. The square root model (6) has proven its efficiency to describe the temperature dependence of bacterial growth in suboptimal temperatures [27]:

$$
\sqrt{\mu_{\max }}=b\left(T-T_{\min }\right) .
$$

In Equation (6), $\mu_{\max }$ is the maximum growth rate at each temperature $(T)$, and $b$ and $T_{\text {min }}$ are the model parameters, with $T_{\min }$ defined as the minimum growth temperature.

2.6. Model Evaluation and Validation. ANOVA was used to evaluate significance and adequacy of the model. Fitting goodness of the model was characterized by the correlation coefficient $\left(a d j-R^{2}\right)$, Akaike information criterion (AIC), and the root mean square error (RMSE). For model validation, bias factors $\left(B_{f}\right)$ on $(7)$ and accuracy factors $\left(A_{f}\right)$ on (8) were calculated with the data selected from literatures [28-30]. The selected data should be (i) describing the behavior of Salmonella were generated in lettuce, (ii) obtained using the traditional plate counts method, and (iii) obtained in the temperature range from 4 to $36^{\circ} \mathrm{C}$. Finally, Salmonella survival data in lettuce at $4^{\circ} \mathrm{C}$ were used to validate the Log-linear model, and growth data in lettuce at 15 and $20^{\circ} \mathrm{C}$ were used to estimate the applicability of $\mu_{\max }$ with the square root model $[29,30]$.

$$
\begin{array}{r}
B_{f}=10\left[\sum_{i=1}^{n} \log \left(M_{\mathrm{obs}} / M_{\text {pred }}\right) / n\right], \\
A_{f}=10 \\
{\left[\sum_{i=1}^{n}\left|\log \left(M_{\mathrm{obs}} / M_{\text {pred }}\right)\right| / n\right],}
\end{array}
$$

where $n$ is the number of trials, $M_{\text {obs }}$ is the observed specific bacterial reductions at $4^{\circ} \mathrm{C}$ or specific growth rate at 15 and $20^{\circ} \mathrm{C}$, and $M_{\text {pred }}$ is the predicted bacterial reductions at $4^{\circ} \mathrm{C}$ or specific growth rate at 15 and $20^{\circ} \mathrm{C}$.

2.7. Statistical Analysis. The results of bacterial growth and survival on samples were analyzed by calculating the means and standard deviations using Excel 2010 (Microsoft, Redmond, WA, USA). Statistical analyses consisted of ANOVA with Duncan's test, using the SPSS 19.0 software (IBM, Chicago, IL, USA). A significant difference was established at $P<0.05$.

\section{Results and Discussion}

3.1. Phenotypic Antibiotic Resistance. As shown in Table 1, S. Typhimurium SA62 and Z62 were susceptible to all 13 


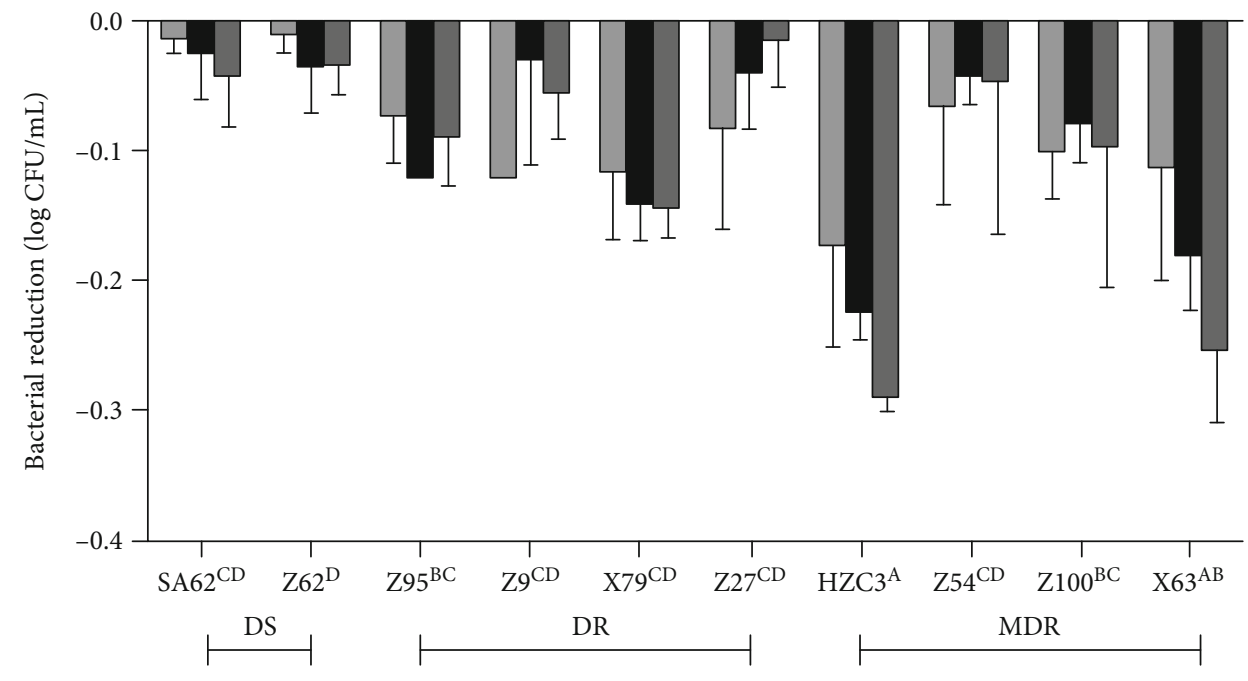

$\square 48 \mathrm{~h}$

口 $72 \mathrm{~h}$

$\square 96 \mathrm{~h}$

(a)

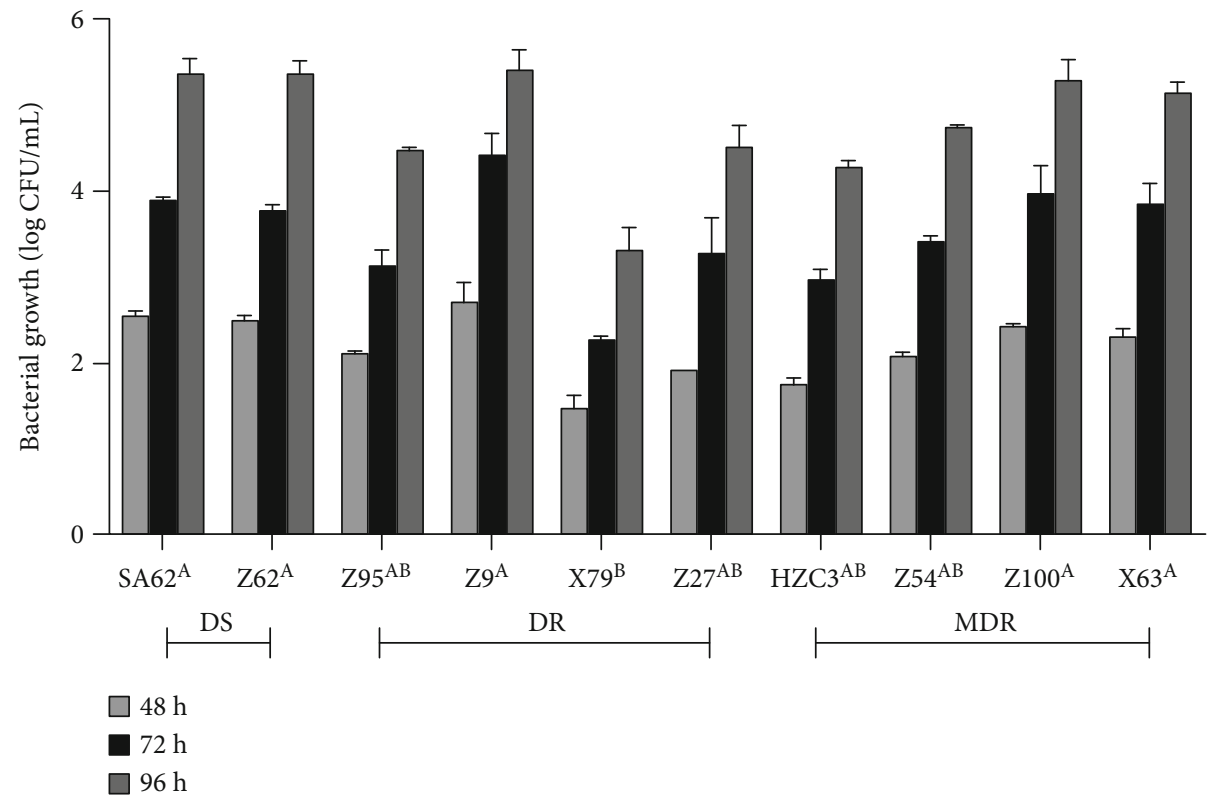

(b)

Figure 1: Continued. 


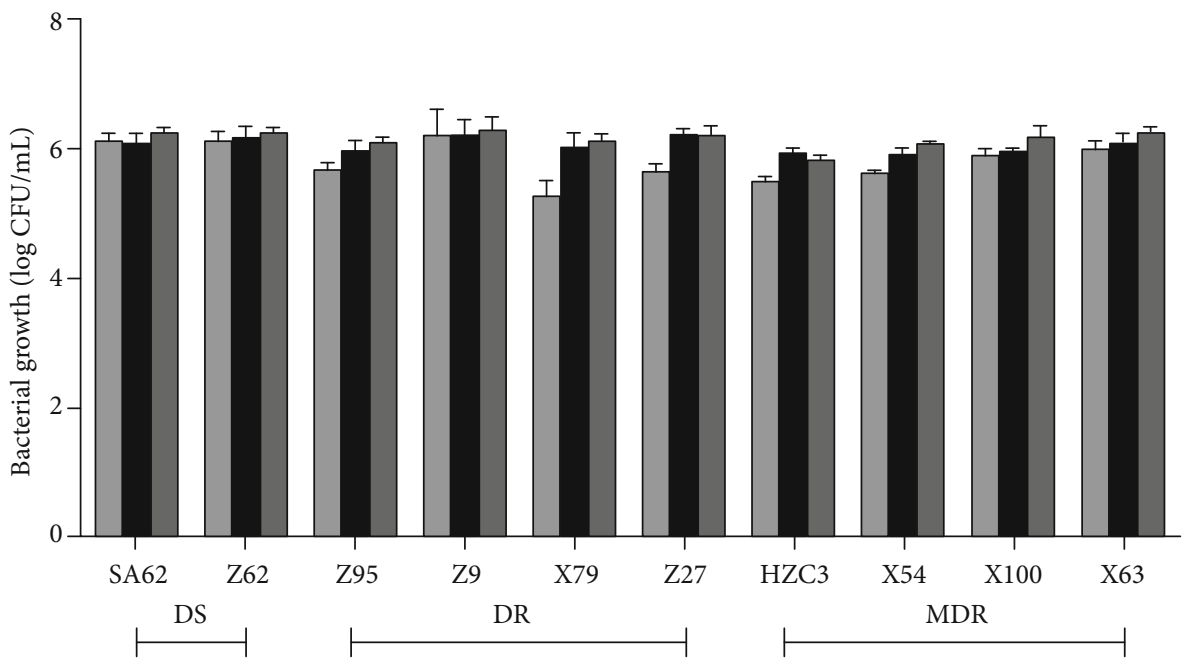

$\square 48 \mathrm{~h}$
$\square 72 \mathrm{~h}$
$\square 96 \mathrm{~h}$

(c)

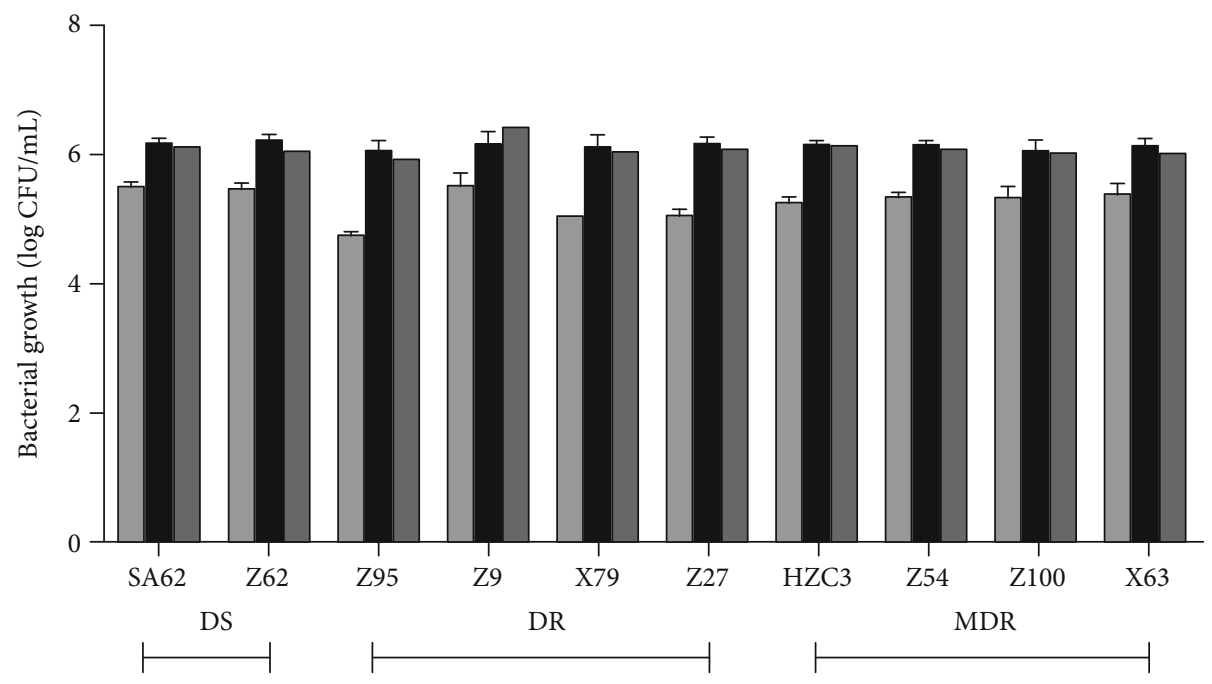

$\square 8 \mathrm{~h}$

口 $24 \mathrm{~h}$

$\square 72 \mathrm{~h}$

(d)

Figure 1: Continued. 


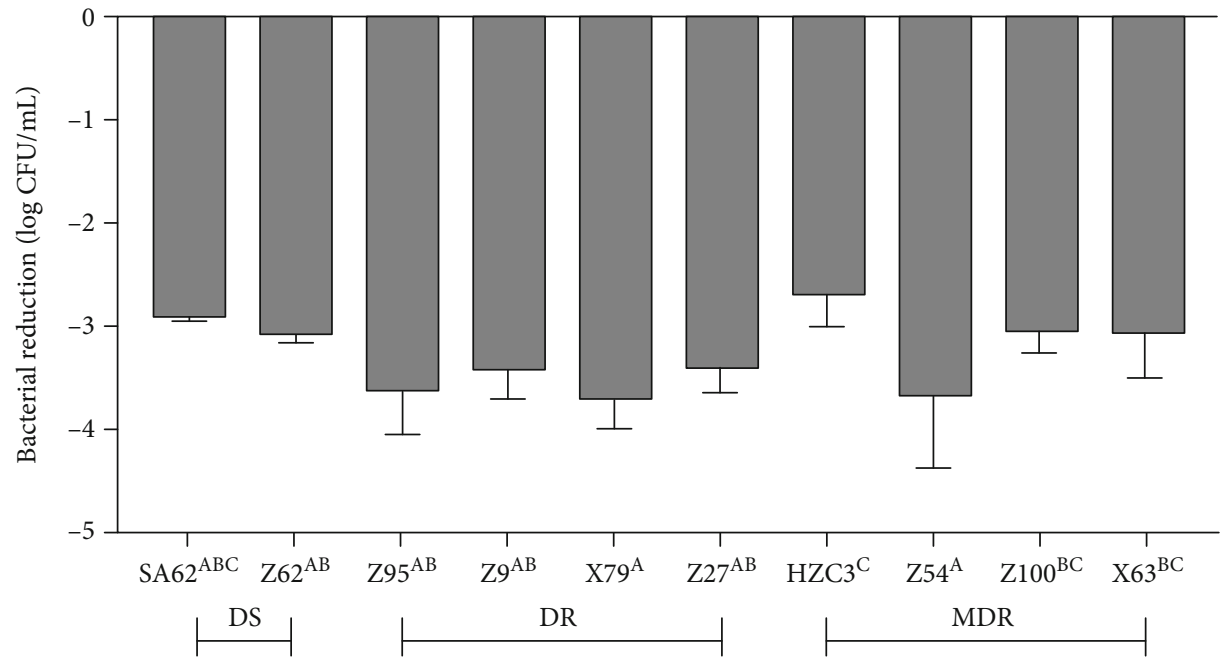

(e)

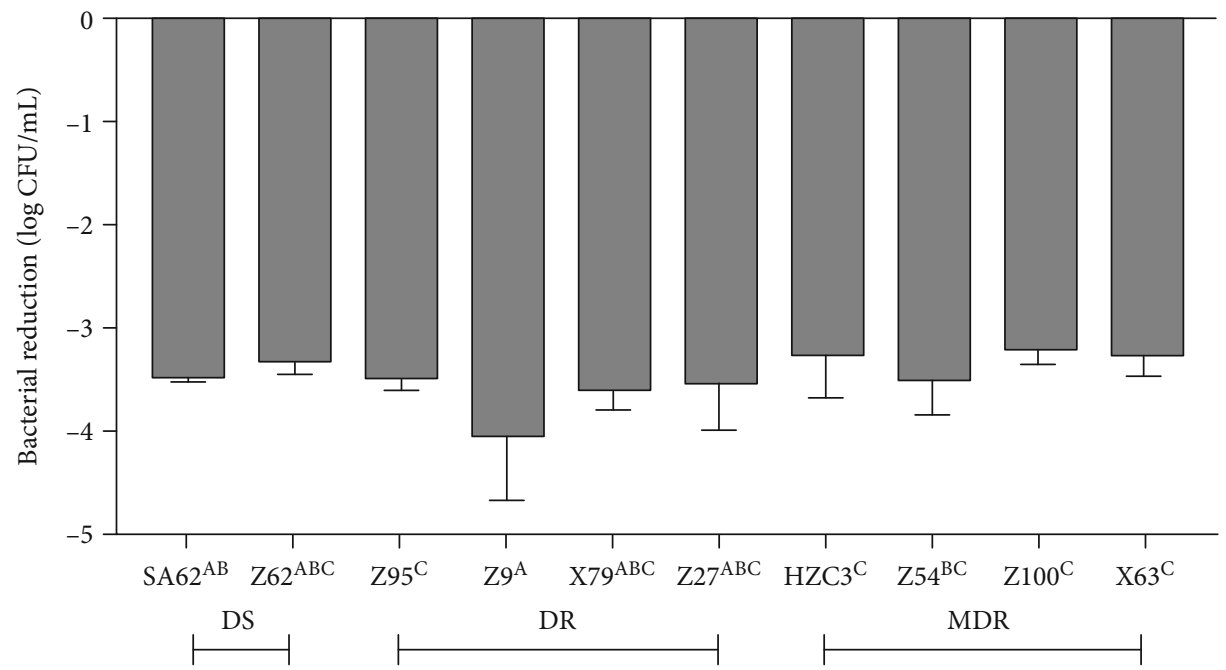

(f)

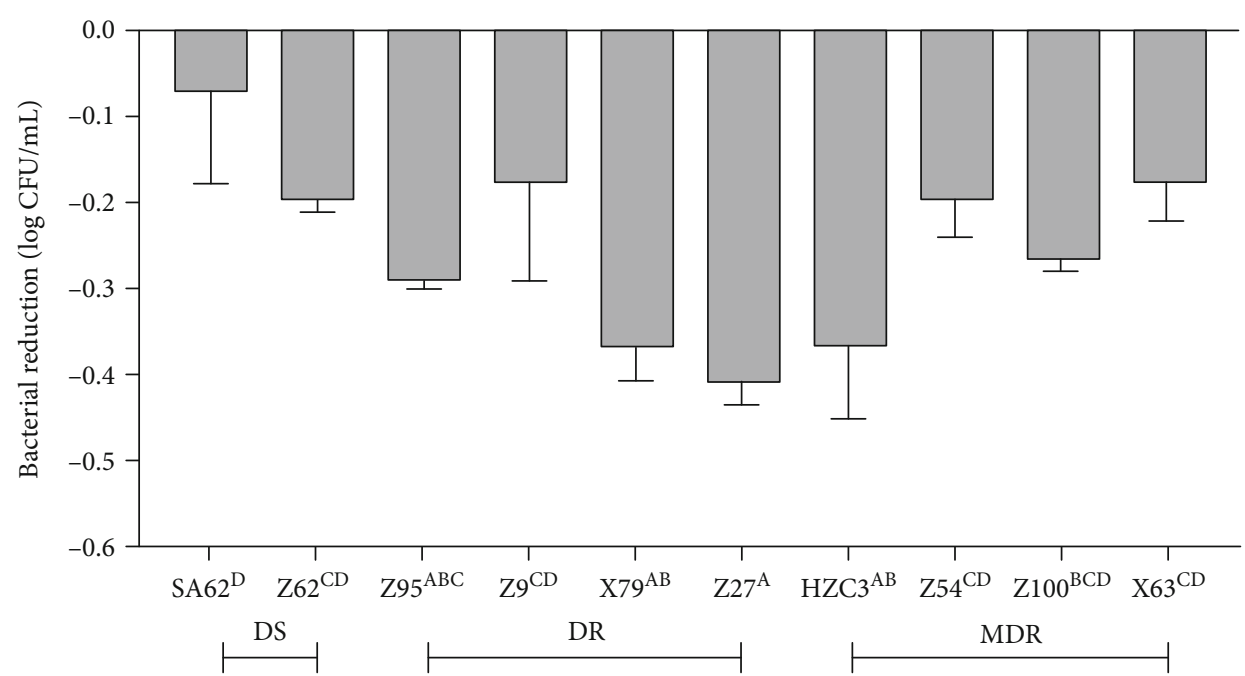

(g)

FIgUre 1: Continued. 


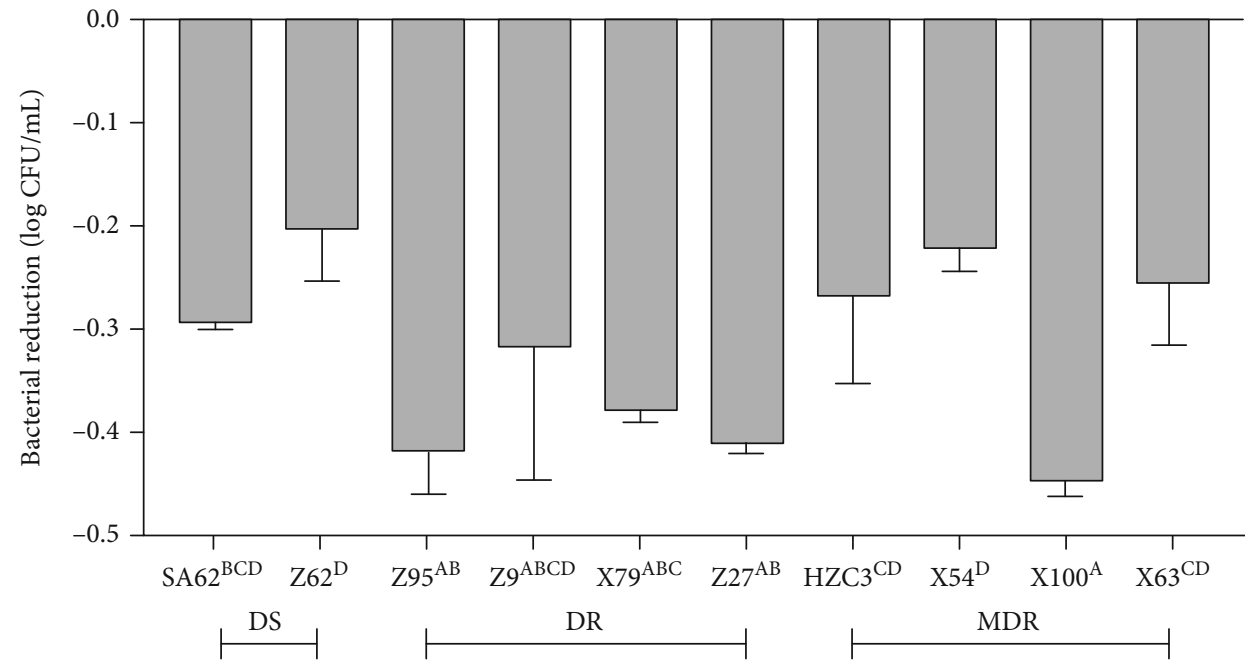

(h)

FIgURE 1: Logarithmic reduction or growth of 10 isolates of $S$. Typhimurium in the suspensions after exposure to storage temperatures at (a) $4^{\circ} \mathrm{C}$, (b) $12^{\circ} \mathrm{C}$, (c) $24^{\circ} \mathrm{C}$, and (d) $36^{\circ} \mathrm{C}$ for $96 \mathrm{~h}$; hot water temperatures at (e) $60^{\circ} \mathrm{C}$ and (f) $75^{\circ} \mathrm{C}$ for 2 min; NaClO concentrations at (g) $100 \mathrm{mg} / \mathrm{L}$ and (h) $200 \mathrm{mg} / \mathrm{L}$ for $10 \mathrm{~min}$. DS: drug-sensitive; DR: drug-resistant; MDR: multidrug-resistant. Uppercase letters represent the results of significant difference analysis with different isolates. Where an uppercase letter is not shown, no statistical difference between all the data is analyzed.

antibiotics; S. Typhimurium Z95, Z9, X79, and Z27 were resistant to one or two antibiotics; and $S$. Typhimurium HZC3, X54, X100 and X63 were resistant to at least three antibiotics and therefore were considered MDR. Of the 10 Salmonella isolates analyzed, six isolates were resistant to FFC, and six isolates were also resistant to TET. A total of 4 Salmonella isolates were resistant to both FFC and TET. These results were consistent with the reported rates from previous study of resistance among Salmonella isolates from other food sources in China [4]. FFC is an antibiotic that is exclusively used in veterinary medicine in China, and TET is commonly used for the treatment of infections in poultry, which could be an explanation for the high rates of resistance towards these antibiotics [31].

3.2. Growth and Survival of Salmonella through Environmental Stress. Logarithmic reduction and growth of 10 isolates of Salmonella in the suspensions after exposure to different storage temperatures, hot water temperatures and $\mathrm{NaClO}$ concentrations are plotted in Figure 1. The results showed that the ranges of reductions in DS, DR, and MDR Salmonella strains after storage at $4^{\circ} \mathrm{C}$ for $96 \mathrm{~h}$ were $0.02-0.07,0.03-0.16$, and $0.02-0.30 \log \mathrm{CFU} / \mathrm{mL}$, respectively (Figure 1(a)). There was a slow trend towards reduction of DS isolates in relation to the others but without statistical difference. No significant differences in bacterial growth with different antibiotic profiles were observed during storage at 12,24 , and $36^{\circ} \mathrm{C}(P>0.05)$ (Figures $1(\mathrm{~b})-$ 1(d)). As shown in Figures 1(e) and 1(f), the reductions of Salmonella isolates in the suspensions at the end of $2 \mathrm{~min}$ treatments were $3.28 \pm 0.35$ and $3.50 \pm 0.24 \log \mathrm{CFU} / \mathrm{mL}$ at 60 and $75^{\circ} \mathrm{C}$, respectively. The reductions of Salmonella isolates in the suspensions were $0.25 \pm 0.10$ and $0.32 \pm 0.09 \log$ $\mathrm{CFU} / \mathrm{mL}$ with 100 and $200 \mathrm{mg} / \mathrm{L}$ of chlorine, respectively
(Figures 1(g) and 1(h)). After heat and chlorine exposure, lower trends towards mortality of DS strains compared with DR or MDR strains were found though without statistical difference (Figures 1(e)-1(h)).

In the test of bacterial storage in lettuce, $S$. Typhimurium HZC3 and SA62 were selected to investigate the difference of bacterial kinetics with different antibiotic resistance profiles during storage. The criteria used to choose these two isolates should be (i) MDR and DS strains, and (ii) there was a larger difference in bacterial reduction between MDR and DS strains to the environmental stress. In Figure 2(a), the bacterial reductions for the MDR S. Typhimurium HZC3 and DS $S$. Typhimurium SA62 in lettuce at the end of $120 \mathrm{~h}$ storage were $1.36 \pm 0.21$ and $0.84 \pm 0.04 \log \mathrm{CFU} / \mathrm{cm}^{2}$ at $4^{\circ} \mathrm{C}$, respectively. Greater bacterial reductions were observed for MDR S. Typhimurium HZC3 at $4^{\circ} \mathrm{C}$ from 56 to $108 \mathrm{~h}$ $(P<0.05)$. The greater growth in lettuce at $12^{\circ} \mathrm{C}$ was observed for DS S. Typhimurium SA62 compared to MDR $S$. Typhimurium HZC3 and was even statistically different $(P<0.05)$ (Figure 2(b)), while there was no significant difference of bacterial growth between DS S. Typhimurium SA62 and MDR S. Typhimurium HZC3 in lettuce storage from 16 to $36^{\circ} \mathrm{C}(P>0.05)$ (Figures $\left.2(\mathrm{c})-2(\mathrm{e})\right)$. Overall, bacterial reductions in the suspensions were lower than that in lettuce. The reason could be that the bacterial on the lettuce surface immediately in contact with cold may be killed. In the study of Food Standards Agency funded data generated at Institute of Food Research (https://browser.combase.cc/), reduction of Salmonella in broth was $0.05 \log \mathrm{CFU} / \mathrm{mL}$ after $72 \mathrm{~h}$ storage at $4^{\circ} \mathrm{C}$, which was lower than that in the iceberg lettuce ( 0.68 log CFU/g) [29].

In this study, there was a rapid trend towards reduction of MDR isolates to cold stress in broth, and significant greater bacterial reductions were observed for MDR $S$. 

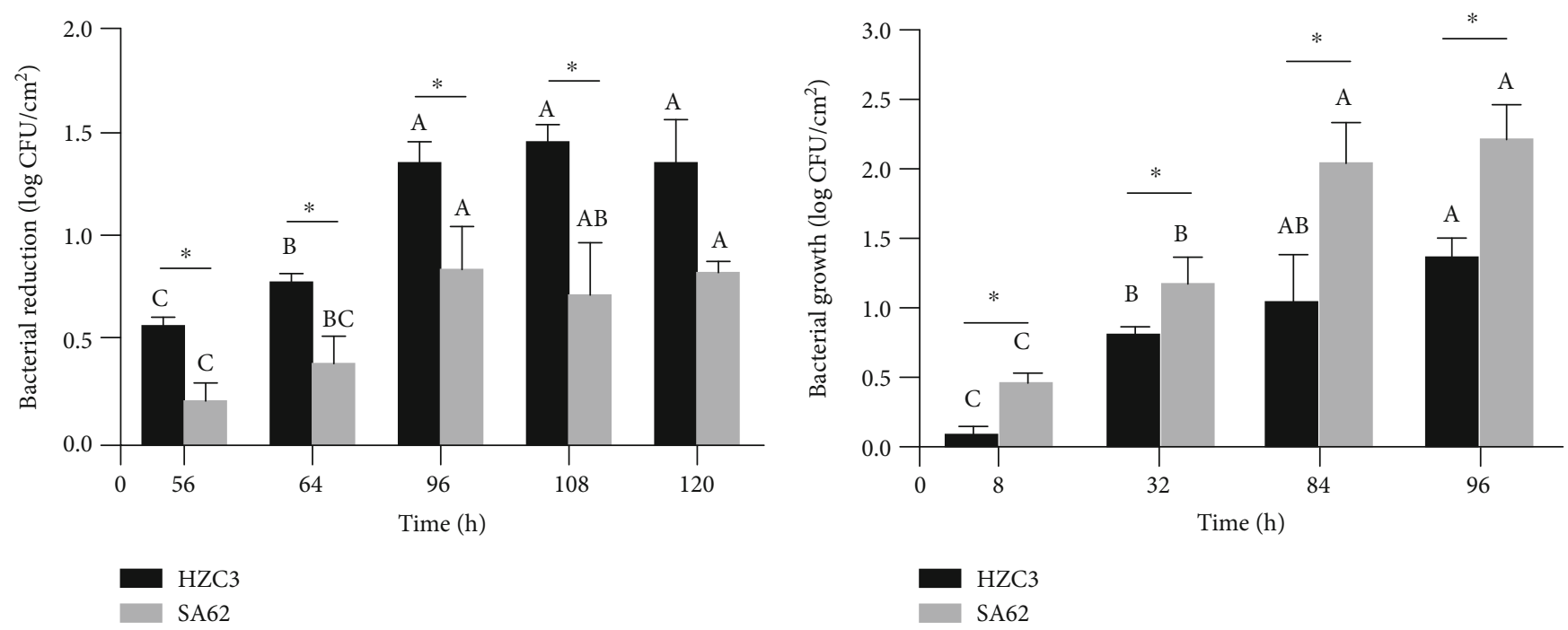

(a)

(b)

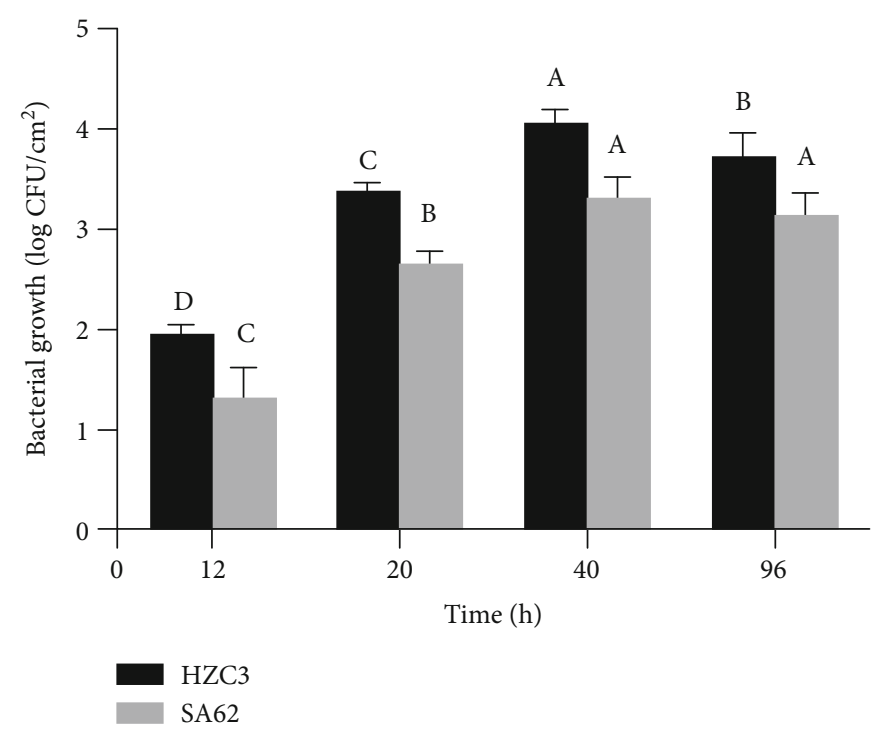

(c)

Figure 2: Continued. 


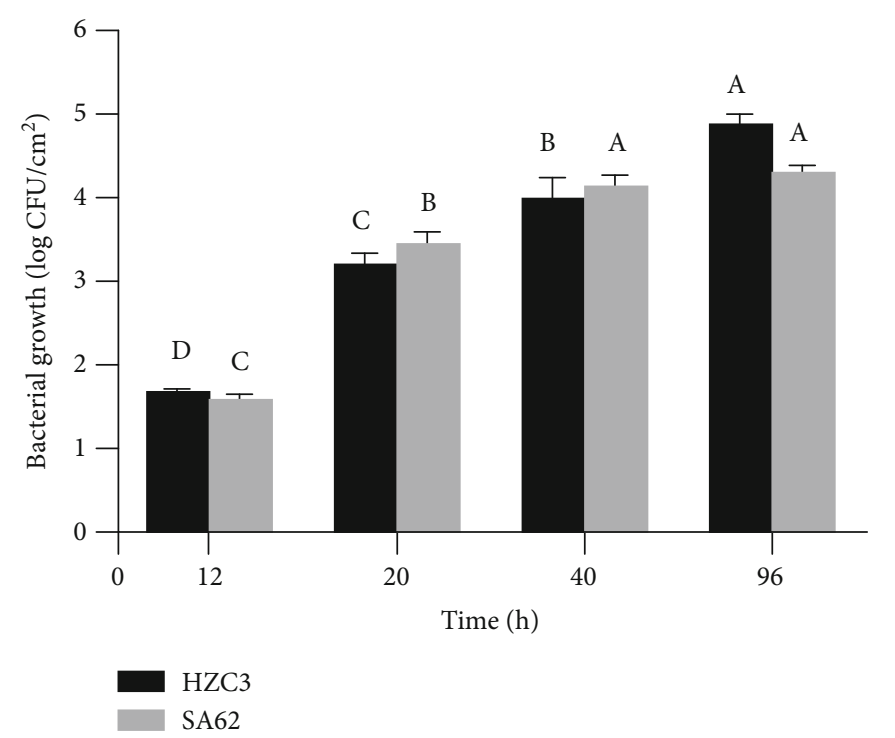

(d)

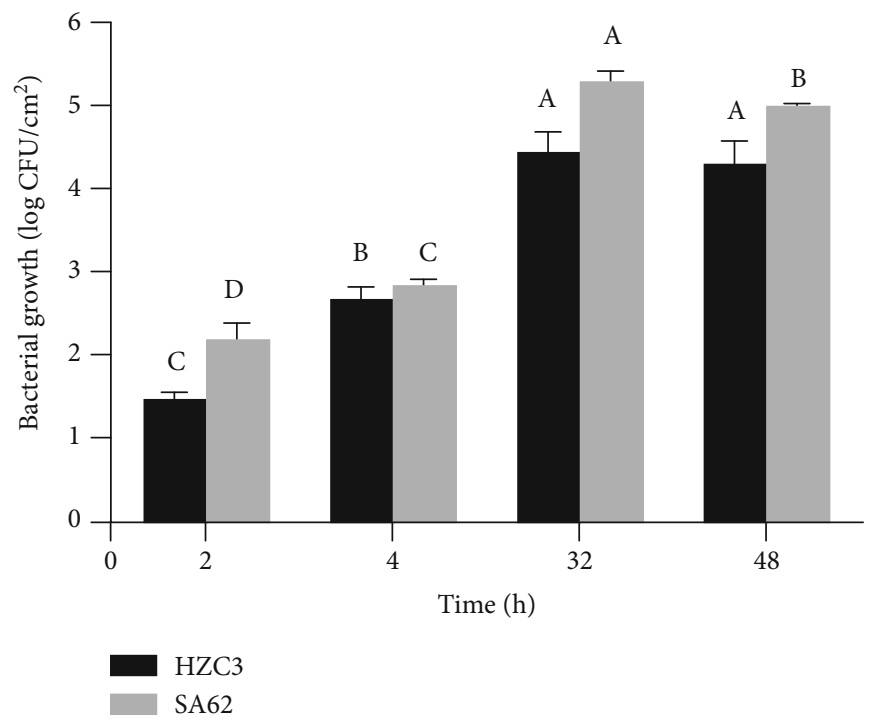

(e)

Figure 2: Bacterial survival and growth of MDR S. Typhimurium HZC3 and DS S. Typhimurium SA62 in lettuce during storage at (a) $4^{\circ} \mathrm{C}$, (b) $12^{\circ} \mathrm{C},(\mathrm{c}) 16^{\circ} \mathrm{C},(\mathrm{d}) 28^{\circ} \mathrm{C}$, and (e) $36^{\circ} \mathrm{C}$. The asterisk $\left(^{*}\right)$ represents significant differences between the two isolates at the same incubation time and temperature. Uppercase letters represent significant differences for the same isolate at the same temperature during the incubation times.

Typhimurium HZC3 in lettuce. No significant differences for the tolerance of antibiotic susceptible and resistant Salmonella were found to thermal and chlorine pressure in the broth. The effects of antibiotic resistance profiles on cold, thermal, and chlorine tolerance of bacteria have been reported in many studies [11, 12, 32]. The observations have been found that the DR E. coli O157:H7 died off significantly faster than the DS strains in both yogurt and juice at $4^{\circ} \mathrm{C}(P<0.05)$ [11]. A previous study found no significant differences for the tolerance of antibiotic susceptible and resistant $L$. monocytogenes to thermal stress at $58^{\circ} \mathrm{C}$ [12]. As well, the chlorine stress of acidified sodium chloride resulted in no difference of the inactivation level for antibiotic resistant and susceptible Salmo- nella [32]. Other studies have shown that DR $L$. monocytogenes and Salmonella were more tolerant than DS strains when exposed to environmental stressors [10, 12]. Sigma factors are the well-known general regulators of bacteria in response to cold and heat stresses [17, 33]. For the chlorine stress, the treatment of Salmonella Enteritidis would induce the overexpression of marRAB operon, a global antibiotic resistance regulator which involved in the production of $A$ crAB efflux pumps to extrude antibiotics [34]. A study found that the inhibition of efflux pumps with reserpine and thioriodazine in antibiotic resistant L. monocytogenes decreased the MIC of disinfectantshydrogen peroxide and benzalkonium chloride by two to eight folds [12]. 


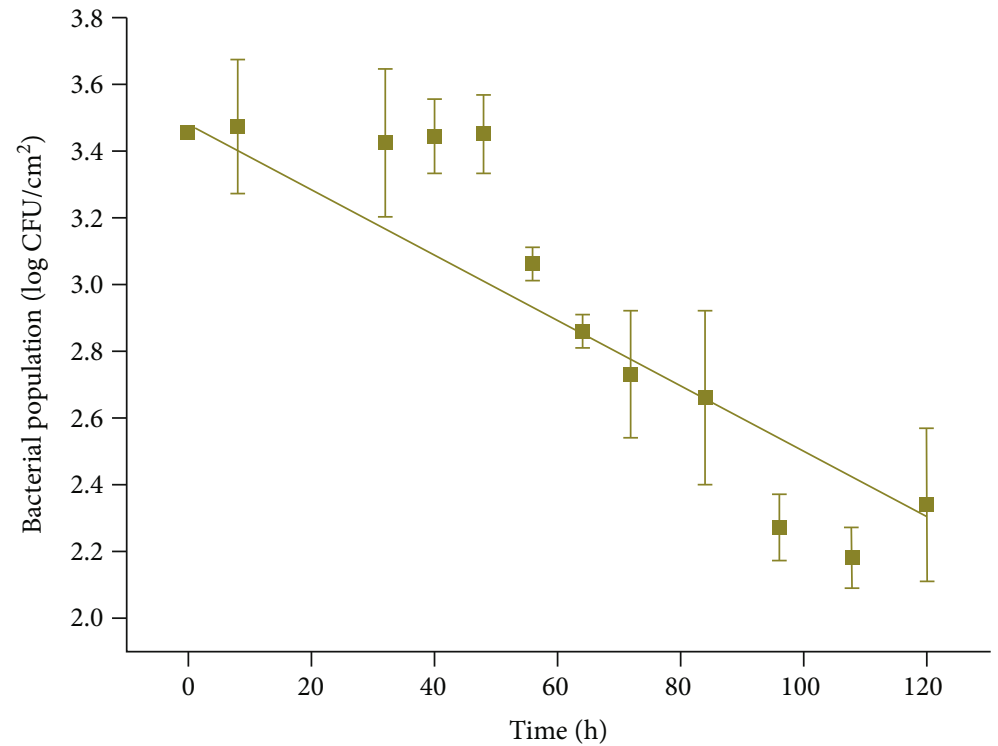

$4^{\circ} \mathrm{C}$

(a)

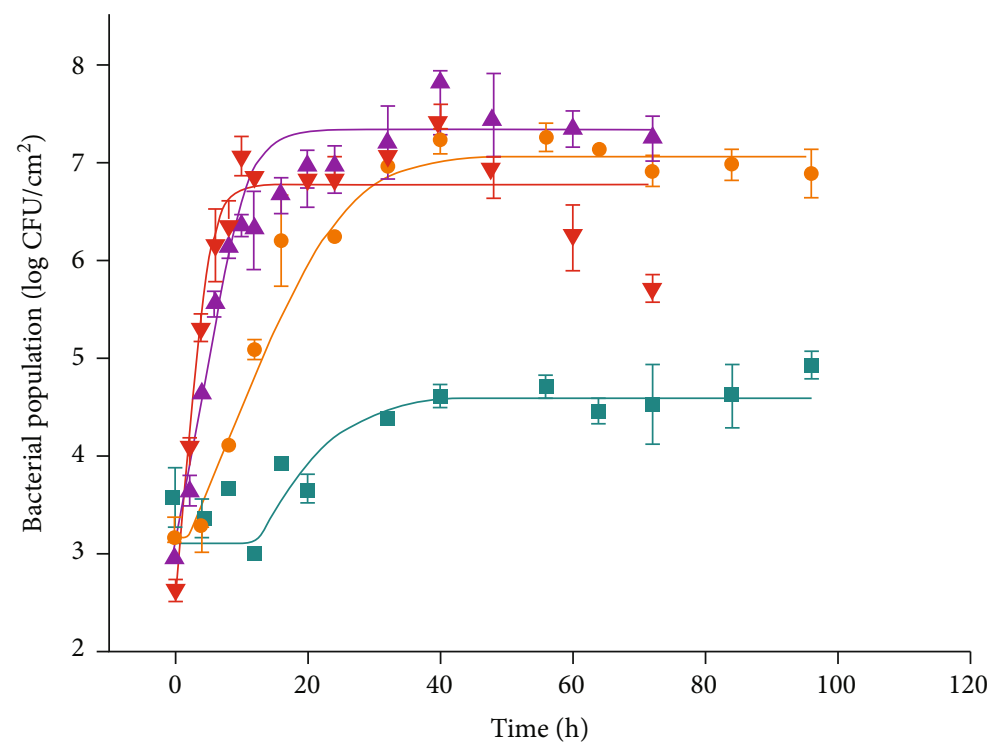

- $12^{\circ} \mathrm{C} \quad 28^{\circ} \mathrm{C}$

- $16^{\circ} \mathrm{C} \quad 36^{\circ} \mathrm{C}$

(b)

Figure 3: Continued. 


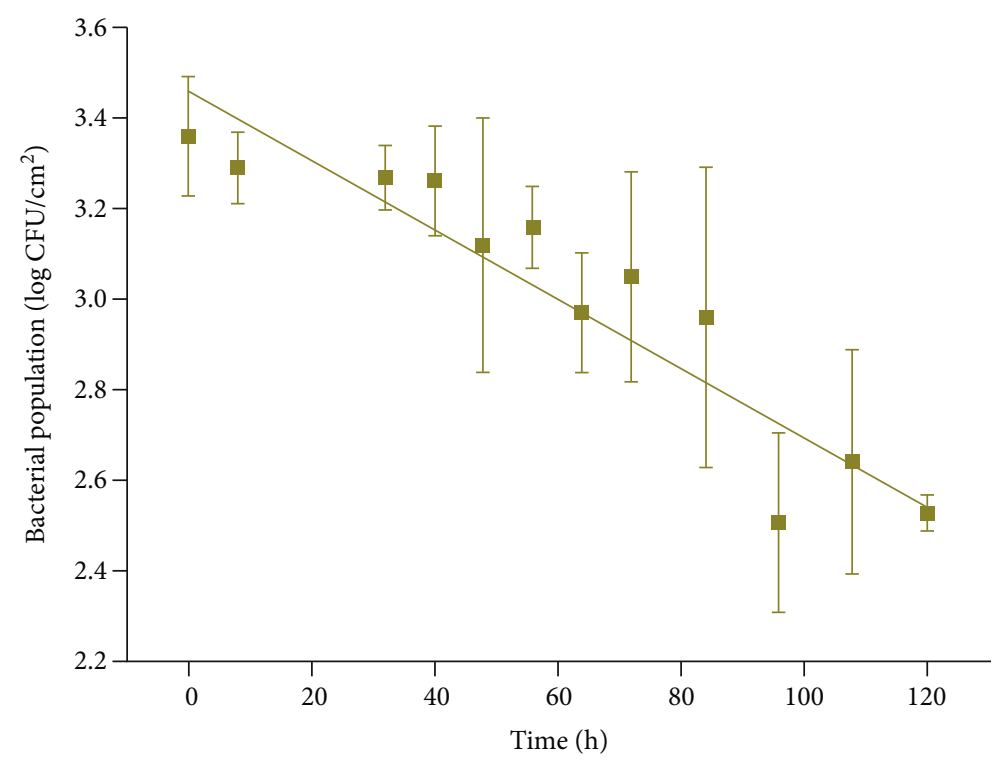

$4^{\circ} \mathrm{C}$

(c)

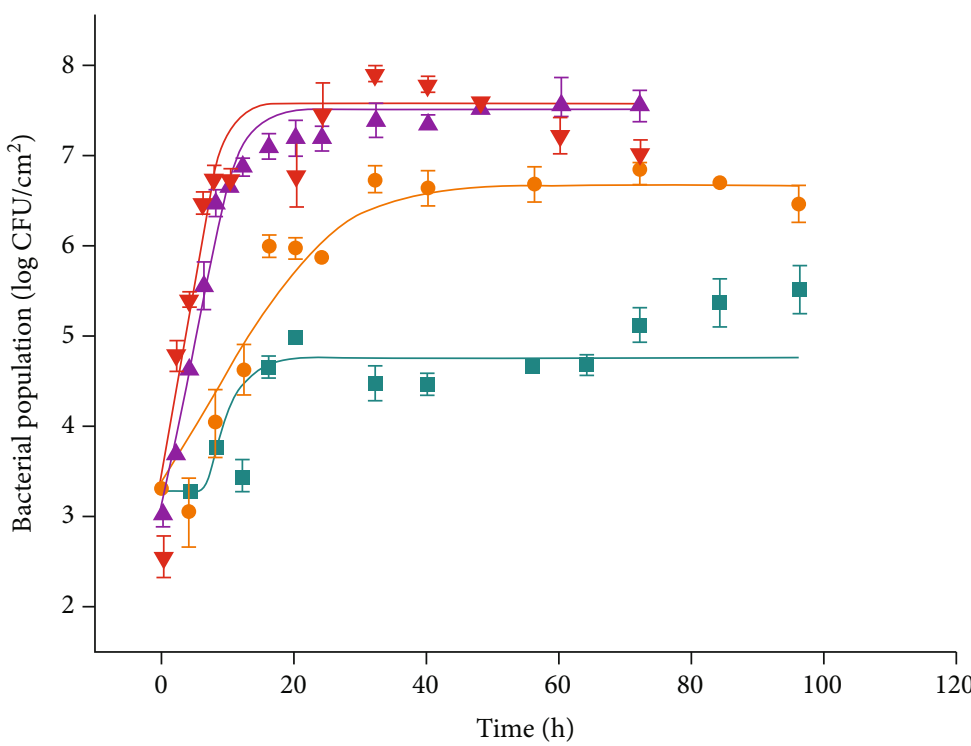

$12^{\circ} \mathrm{C} \quad \triangle \quad 28^{\circ} \mathrm{C}$

$16^{\circ} \mathrm{C} \nabla 36^{\circ} \mathrm{C}$

(d)

Figure 3: Log-linear and Huang models fitting the survival and growth of MDR S. Typhimurium HZC3 and DS S. Typhimurium SA62 in lettuce storage: (a) HZC3 at $4^{\circ} \mathrm{C}$; (b) $\mathrm{HZC} 3$ at $12,16,28$, and $36^{\circ} \mathrm{C}$; (c) SA62 at $4^{\circ} \mathrm{C}$; (d) SA62 at $12,16,28$, and $36^{\circ} \mathrm{C}$.

3.3. Parameter Estimates of the Microbial Models in Lettuce. Significant differences in bacterial reductions were found for MDR S. Typhimurium HZC3 and DS S. Typhimurium SA62 strains that were related to storage time at $4^{\circ} \mathrm{C}(P<0.05)$. The target $a d j-R^{2}(>0.9)$ and RMSE $(<0.2)$ values were reached suggesting that the Log-linear model was reasonably accurate in describing these effects (Figure 3 and Table 2). The Log-linear model assumes a homogeneous bacterial die-off rate, and therefore, a linear curve was applied. A mechanistic explanation for this was that bacterial death
TABle 2: Parameter estimates and statistical analysis of the Loglinear model fitted to MDR $S$. Typhimurium HZC3 and DS S. Typhimurium SA62 survival curves at $4^{\circ} \mathrm{C}$.

\begin{tabular}{lccccc}
\hline Strain & $\log N_{0}$ & $D$ & $a d j-R^{2}$ & AIC & RMSE \\
\hline HZC3 & 3.48 & 102.84 & 0.92 & -38.03 & 0.15 \\
SA62 & 3.46 & 131.27 & 0.95 & -35.84 & 0.17 \\
\hline
\end{tabular}

$\log N_{0}$ : the initial bacterial population in lettuce $\left(\mathrm{CFU} / \mathrm{cm}^{2}\right) ; D$ : the decimal reduction time $(\mathrm{h})$ at a specific treatment temperature; adj- $R^{2}$ : the correlation coefficient; AIC: Akaike information criterion; RMSE: the root mean square error. 
TAble 3: Parameter estimates and statistical analysis of the Modified Gompertz, Huang, Logistic, and Baranyi models fitted to MDR S. Typhimurium HZC3 and DS S. Typhimurium SA62 growth curves at $12,16,28$, and $36^{\circ} \mathrm{C}$.

\begin{tabular}{|c|c|c|c|c|c|c|c|c|c|}
\hline Model & Strain & $\begin{array}{c}\text { Temperature } \\
\left({ }^{\circ} \mathrm{C}\right)\end{array}$ & $\begin{array}{c}\log N_{0}(\mathrm{CFU} / \\
\left.\mathrm{cm}^{2}\right)\end{array}$ & $\begin{array}{l}\lambda / h_{0} \\
(\mathrm{~h})\end{array}$ & $\begin{array}{c}\mu_{\max }(\log \mathrm{CFU} / \\
\left.\mathrm{cm}^{2} / \mathrm{h}\right)\end{array}$ & $\log N_{\max }(\mathrm{CFU} /$ & $a d j-R^{2}$ & AIC & RMSE \\
\hline \multirow{8}{*}{$\begin{array}{l}\text { Modified } \\
\text { Gompertz }\end{array}$} & \multirow{4}{*}{ HZC3 } & 12 & 3.43 & 14.27 & 0.07 & 4.65 & 0.82 & -22.19 & 0.26 \\
\hline & & 16 & 3.08 & 4.12 & 0.31 & 7.01 & 0.98 & -30.17 & 0.22 \\
\hline & & 28 & 2.93 & 0.00 & 0.47 & 7.22 & 0.96 & -34.54 & 0.29 \\
\hline & & 36 & 2.61 & 0.10 & 0.83 & 7.00 & 0.97 & -39.07 & 0.24 \\
\hline & \multirow{4}{*}{ SA62 } & 12 & 3.30 & 11.81 & 0.47 & 4.90 & 0.70 & 19.40 & 0.39 \\
\hline & & 16 & 3.14 & 4.71 & 0.27 & 6.62 & 0.96 & 31.21 & 0.27 \\
\hline & & 28 & 2.63 & 0.00 & 0.57 & 7.36 & 0.99 & -47.47 & 0.14 \\
\hline & & 36 & 2.56 & 0.00 & 0.47 & 7.52 & 0.89 & 36.21 & 0.34 \\
\hline \multirow{8}{*}{ Huang } & \multirow{5}{*}{ HZC3 } & 12 & 3.41 & 12.32 & 0.10 & 4.66 & 0.84 & -23.10 & 0.25 \\
\hline & & 16 & 3.15 & 3.66 & 0.25 & 7.00 & 0.97 & -28.15 & 0.24 \\
\hline & & 28 & 3.04 & 0.00 & 0.39 & 7.19 & 0.95 & -26.16 & 0.33 \\
\hline & & 36 & 2.61 & 0.00 & 0.69 & 6.98 & 0.97 & -36.24 & 0.24 \\
\hline & & 12 & 3.28 & 6.11 & 0.18 & 4.94 & 0.88 & 20.21 & 0.43 \\
\hline & \multirow{3}{*}{ SA62 } & 16 & 3.19 & 4.21 & 0.23 & 6.63 & 0.96 & 31.20 & 0.27 \\
\hline & & 28 & 3.01 & 0.37 & 0.47 & 7.33 & 0.99 & -41.86 & 0.17 \\
\hline & & 36 & 2.56 & 0.00 & 0.76 & 7.31 & 0.92 & -17.38 & 0.42 \\
\hline \multirow{8}{*}{ Logistic } & \multirow{4}{*}{ HZC3 } & 12 & 3.43 & 24.63 & 0.21 & 4.66 & 0.82 & -31.81 & 0.26 \\
\hline & & 16 & 3.14 & 11.64 & 0.25 & 7.05 & 0.98 & -35.86 & 0.21 \\
\hline & & 28 & 2.89 & 5.25 & 0.63 & 7.48 & 0.98 & -39.12 & 0.21 \\
\hline & & 36 & 2.62 & 3.11 & 0.55 & 7.18 & 0.98 & -38.57 & 0.23 \\
\hline & \multirow{4}{*}{ SA62 } & 12 & 3.30 & 34.06 & 0.17 & 5.93 & 0.67 & -20.35 & 0.41 \\
\hline & & 16 & 2.87 & 11.47 & 0.37 & 6.70 & 0.95 & -32.94 & 0.26 \\
\hline & & 28 & 3.28 & 5.39 & 0.43 & 7.45 & 0.99 & -61.42 & 0.11 \\
\hline & & 36 & 3.30 & 1.17 & 0.90 & 7.91 & 0.91 & -31.43 & 0.30 \\
\hline \multirow{8}{*}{ Baranyi } & \multirow{5}{*}{ HZC3 } & 12 & 3.56 & -0.91 & 0.10 & 4.72 & 0.76 & -21.95 & 0.30 \\
\hline & & 16 & 3.14 & -1.62 & 0.32 & 6.97 & 0.97 & -26.34 & 0.24 \\
\hline & & 28 & 3.07 & 13.74 & 0.39 & 7.19 & 0.95 & -25.29 & 0.33 \\
\hline & & 36 & 2.61 & 67.54 & 0.69 & 6.98 & 0.97 & -9.28 & 0.24 \\
\hline & & 12 & 3.14 & 0.00 & 0.18 & 4.94 & 0.64 & 19.91 & 0.43 \\
\hline & \multirow{3}{*}{ SA62 } & 16 & 2.22 & 4.58 & 0.23 & 6.62 & 0.95 & 31.18 & 0.28 \\
\hline & & 28 & 2.84 & 6.14 & 0.47 & 7.33 & 0.98 & -41.30 & 0.18 \\
\hline & & 36 & 4.45 & 0.00 & 0.44 & 7.46 & 0.86 & 32.34 & 0.38 \\
\hline
\end{tabular}

$\lambda$ : the lag time (h); $h_{0}$ : the physiological state of the microorganism; $\mu_{\max }$ : the maximum specific growth rate $\left(\log \mathrm{CFU} / \mathrm{cm}^{2} / \mathrm{h}\right) ; \log N_{\max }:$ maximum bacterial populations $\left(\mathrm{CFU} / \mathrm{cm}^{2} / \mathrm{h}\right)$.

was the result of inactivation of some critical enzyme or enzyme system and governed by first-order inactivation kinetics [35].

Significant differences in Salmonella growth in lettuce were found at $12,16,28$, and $36^{\circ} \mathrm{C}$ over time $(P<0.05)$. As the incubation temperature was increased, the lag phases of Salmonella were shortened while the growth rates increased [36]. The Modified Gompertz, Huang, Logistic, and Baranyi models were used to fit both MDR $S$. Typhimurium HZC3 and DS S. Typhimurium SA62 growth at 12, 16, 28, and $36^{\circ} \mathrm{C}$. The results of the parameter estimates and statistical analysis indicated that the Huang models agreed reasonably well with the observed data (Table 3). The Huang model was successfully used to describe the growth kinetics of L. monocytogenes with and without cold-adaption, on fresh-cut cantaloupe under different storage temperatures [37]. Besides, Huang primary model is proper than other models for describing the growth of $S$. aureus in ready-to-eat cooked rice with pork floss [38]. The Huang model is based on the fundamental observation of the classical bacterial growth process that exhibits the three different phases of growth: lag, exponential, and stationary as well as adaption in the lag phase. This model utilizes a transition function to simulate bacterial adaption and to define the lag phase of a growth curve. This allows the model to transit smoothly from the lag phase to the exponential phase $[38,39]$. 


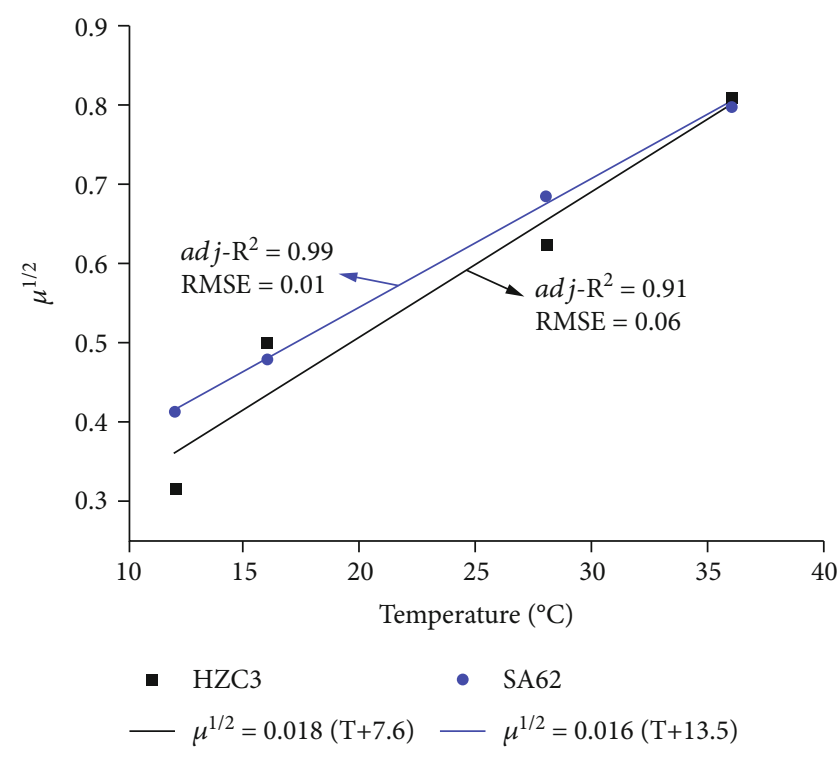

Figure 4: Square root model of the maximum growth rates of MDR S. Typhimurium HZC3 and DS S. Typhimurium SA62 in lettuce at different storage temperatures. $\mu$ values were obtained from the Huang model at each temperature.

TABLE 4: $A_{f}$ and $B_{f}$ values used for the predictive models of MDR $S$. Typhimurium HZC3 and DS S. Typhimurium SA62.

\begin{tabular}{lcccc}
\hline Temperature $\left({ }^{\circ} \mathrm{C}\right)$ & Model & Strain & $A_{f}$ & $B_{f}$ \\
\hline \multirow{2}{*}{4} & \multirow{2}{*}{ Log-linear } & HZC3 & 1.85 & 1.85 \\
& & SA62 & 1.87 & 1.87 \\
\hline \multirow{2}{*}{$12,16,28,36$} & \multirow{2}{*}{ Square root } & HZC3 & 1.39 & 1.39 \\
& & SA62 & 1.15 & 1.15 \\
\hline
\end{tabular}

$A_{f}:$ accuracy factor; $B_{f}:$ bias factor.

A square root model was developed to describe the effect of temperature on the growth rates of $S$. Typhimurium HZC3 and SA62 derived from the Huang model. The relationships between the growth rates and temperature for both S. Typhimurium HZC3 and SA62 strains followed a linear trend (Figure 4). The model for S. Typhimurium HZC3 and $S$. Typhimurium SA62 was in acceptable agreement between predictions and observations (Figure 4). Similar to our findings, a previous study concluded that the square root model could adequately describe the individual effects of temperature $\left(7 \sim 30^{\circ} \mathrm{C}\right)$ on the growth rate of $S$. Enterica and L. monocytogenes in lettuce [15].

3.4. Model Validation and Its Application in QMRA. The values of $A_{f}$ and $B_{f}$ for the developed models are shown in Table 4 . For the bacterial survival model at $4^{\circ} \mathrm{C}$, the values of $A_{f}$ and $B_{f}$ for the MDR $S$. Typhimurium HZC3 and DS $S$. Typhimurium SA62 ranged from 1.85 to 1.87 , and for the bacterial growth at 12 to $36^{\circ} \mathrm{C}$, the $A_{f}$ and $B_{f}$ values of the square root model for the $S$. Typhimurium HZC3 and SA62 strains ranged from 1.15 to 1.39 , indicating the devel- oped models showed a satisfactory performance to predict the bacterial populations. The $A_{f}$ takes the average distance between every point and the line of equivalence as a measure of how close; on average, the predictions are to the observations $[40,41]$. Satisfactory $B_{f}$ limits are more difficult to define because limits of acceptability are related to the specific application of the model. Ideally, predictive models would have $A_{f}=B_{f}=1$. When compared to independently published data, $B_{f}$ values in the range 0.6-3.99 were acceptable for the growth rates of pathogens and spoilage organisms [40]. The $A_{f}$ value is indicating that $85-87 \%$ of the data is over- or underestimated. The validation data were selected from Combase Database (https://browser.combase .cc/). Only one literature study was available on S. Typhimurium 14028 at $4^{\circ} \mathrm{C}$ in iceberg lettuce from Combase Database, which was used to validate the model. More research data on bacterial survival and growth with different antibiotic resistance in lettuce is needed in the future.

Instead of considering all hazard strains as equally likely to cause disease, this study could improve hazard identification by focusing on those strains with different antibiotic resistance profiles and could be used to stratify hazards into strains that are expected to behave difference, e.g., in terms of growth, survival, or response to antibiotic resistance [42]. The QMRA input parameters can be tailored to each strain accordingly, making it possible to capture the variability in the strains of interest while decreasing the uncertainty in the model [43].

\section{Conclusions}

In this study, there was a slow trend towards reduction of DS isolates in relation to the others to the cold, heat, and chlorine stress but without significant difference. In broth, there was a rapid trend towards reduction of MDR isolates to cold stress, and significant greater bacterial reductions were observed for MDR S. Typhimurium HZC3 in lettuce Loglinear models were also able to describe bacterial reductions in lettuce during storage at $4^{\circ} \mathrm{C}$. The Huang model was the best fit model to describe bacterial growth at $12,16,28$, and $36^{\circ} \mathrm{C}$, and a square root model was used to describe the effect of temperature on the parameters of growth rates. The generated models could provide parts of the input data for microbial risk assessment of Salmonella with different antibiotic resistance profile in lettuce and make it possible to capture the variability in the strains of interest while decreasing the uncertainty in some model input parameters.

\section{Data Availability}

The data used to support the findings of this study are included within the article.

\section{Conflicts of Interest}

The authors declare that they do not have any conflict of interest. 


\section{Authors' Contributions}

Xingning Xiao and Biao Tang contributed equally.

\section{Acknowledgments}

This research was supported by the Ministry of Agriculture and Rural Affairs of the People's Republic of China (14205054). The authors thank Yang Qu and Tian He for their help in the experiments.

\section{References}

[1] L. Zhang, Y. Fu, Z. Xiong et al., "Highly prevalent multidrugresistant Salmonella from chicken and pork meat at retail markets in Guangdong, China," Frontiers in Microbiology, vol. 9, p. $2104,2018$.

[2] Y. Wadamori, R. Gooneratne, and M. A. Hussain, "Outbreaks and factors influencing microbiological contamination of fresh produce," Journal of the Science of Food and Agriculture, vol. 97, no. 5, pp. 1396-1403, 2017.

[3] S. De Oliveira Elias, T. B. Noronha, and E. C. Tondo, "Salmonella spp. and Escherichia coli O157:H7 prevalence and levels on lettuce: A systematic review and meta-analysis," Food Microbiology, vol. 84, p. 103217, 2019.

[4] X. Yang, Q. Wu, J. Huang et al., "Prevalence and characterization of Salmonella isolated from raw vegetables in China," Food Control, vol. 109, article 106915, 2020.

[5] T. P. Oscar, "Predictive model for growth of Salmonella Newport on Romaine lettuce," Journal of Food Safety, vol. 40, no. 3, article 12786, 2020.

[6] S. P. Reddy, H. Wang, J. K. Adams, and P. C. Feng, "Prevalence and characteristics of Salmonella serotypes isolated from fresh produce marketed in the United States," Journal of Food Protection, vol. 79, no. 1, pp. 6-16, 2016.

[7] D. Hwang, S. M. Kim, and H. J. Kim, "Modelling of tetracycline resistance gene transfer by commensal Escherichia coli food isolates that survived in gastric fluid conditions," International Journal of Antimicrobial Agents, vol. 49, no. 1, pp. 8187, 2017.

[8] G. B. Michael and S. Schwarz, "Antimicrobial resistance in zoonotic nontyphoidal Salmonella: Analarming trend?," Clincial Microbiology Infection, vol. 22, pp. 968-974, 2016.

[9] R. Huang and H. Chen, "Evaluation of inactivating Salmonella on iceberg lettuce shreds with washing process in combination with pulsed light, ultrasound and chlorine," International Journal of Food Microbiology, vol. 285, pp. 144-151, 2018.

[10] Y. Ma, G. Lan, C. Li et al., "Stress tolerance of Staphylococcus aureus with different antibiotic resistance profiles," Microbial Pathogenesis, vol. 133, p. 103549, 2019.

[11] G. Duffy, C. Walsh, I. S. Blair, and D. A. McDowell, "Survival of antibiotic resistant and antibiotic sensitive strains of $E$. coli O157 and E. coli O26 in food matrices," International Journal of Food Microbiology, vol. 109, no. 3, pp. 179-186, 2006.

[12] N. Komora, C. Bruschi, R. Magalhães, V. Ferreira, and P. Teixeira, "Survival of Listeria monocytogenes with different antibiotic resistance patterns to food-associated stresses," International Journal of Food Microbiology, vol. 245, pp. 7987, 2017.
[13] J. M. Membré and G. Boué, "Quantitative microbiological risk assessment in food industry: theory and practical application," Food Research International, vol. 106, pp. 1132-1139, 2018.

[14] B. Omac, R. G. Moreira, A. Castillo, and E. Castell-Perez, "Growth of Listeria monocytogenes and Listeria innocua on fresh baby spinach leaves: Effect of storage temperature and natural microflora," Postharvest Biology and Technology, vol. 100, pp. 41-51, 2015.

[15] S. Sant'Ana, B. D. G. M. Franco, and D. W. Schaffner, "Modeling the growth rate and lag time of different strains of_Salmonella enterica_ and Listeria monocytogenes in ready-to-eat lettuce," Food Microbiology, vol. 30, no. 1, pp. 267-273, 2012.

[16] O. Veys, S. D. O. Elias, I. Sampers, and E. C. Tondo, "Modelling the Growth of Salmonella spp. and Escherichia Coli O157 on Lettuce," Procedia Food Science, vol. 7, pp. 168-172, 2016.

[17] X. Liao, Y. Ma, E. B. Daliri et al., "Interplay of antibiotic resistance and food-associated stress tolerance in foodborne pathogens," Trends in Food Science \& Technology, vol. 95, pp. 97106, 2020.

[18] T. Ross and T. A. McMeekin, "Modeling microbial growth within food safety risk assessments," Risk Analysis, vol. 23, no. 1, pp. 179-197, 2003.

[19] CLSI, "Performance standards for antimicrobial susceptibility testing: 29th informational supplement," in M100Ed29, CLSI, Wayne, PA, USA, 2019.

[20] EUCAST, The European Committee on Antimicrobial Susceptibility Testing Breakpoint Tables for Interpretation of MICs and Zone Diameters. Version 7.1, pp. 203-209, 2017.

[21] H. Wang and E. T. Ryser, "Quantitative transfer and sanitizer inactivation of Salmonella during simulated commercial dicing and conveying of tomatoes," Food Control, vol. 107, p. 106762, 2020.

[22] M. H. Zwietering, I. Jongenburger, F. M. Rombouts, and K. Van't Riet, "Modeling of the bacterial growth curve," Applied and Environmental Microbiology, vol. 56, no. 6, pp. 1875-1881, 1990.

[23] M. Li, A. Pradhan, W. Wang, and Y. Li, "Prediction of Listeria innocua survival in fully cooked chicken breast products during postpackage thermal treatment," Poultry Science, vol. 92, no. 3, pp. 827-835, 2013.

[24] L. Huang, "Optimization of a new mathematical model for bacterial growth," Food Control, vol. 32, no. 1, pp. 283-288, 2013.

[25] V. K. Juneja, M. Valenzuela Melendres, L. Huang, V. Gumudavelli, J. Subbiah, and H. Thippareddi, "Modeling the effect of temperature on growth of Salmonella in chicken," Food Microbiology, vol. 24, no. 4, pp. 328-335, 2007.

[26] J. Baranyi and T. A. A. Roberts, "A dynamic approach to predicting bacterial growth in food," International Journal of Food Microbiology, vol. 23, no. 3-4, p. 277, 1994.

[27] D. A. Ratkowsky, J. Olley, T. A. McMeekin, and A. Ball, "Relationship between temperature and growth rate of bacterial cultures," Journal of Bacteriology, vol. 149, no. 1, pp. 1-5, 1982.

[28] J. Baranyi, C. Pin, and T. Ross, "Validating and comparing predictive models," International Journal of Food Microbiology, vol. 48, no. 3, pp. 159-166, 1999.

[29] J. Chang and T. J. Fang, "Survival of Escherichia coli O157:H7 and Salmonella enterica serovars Typhimurium in iceberg lettuce and the antimicrobial effect of rice vinegar against E. coli 
O157:H7," Food Microbiology, vol. 24, no. 7-8, pp. 745-751, 2007.

[30] S. Koseki and S. Isobe, "Prediction of pathogen growth on iceberg lettuce under real temperature history during distribution from farm to table," International Journal of Food Microbiology, vol. 104, no. 3, pp. 239-248, 2005.

[31] T. P. Mthembu, O. T. Zishiri, and M. E. El Zowalaty, "Molecular detection of multidrug-resistant Salmonella isolated from livestock production systems in South Africa," Infection and Drug Resistance, vol. 12, pp. 3537-3548, 2019.

[32] M. K. Hughes, S. Yanamala, M. S. Francisco, G. H. Loneragan, M. F. Miller, and M. M. Brashears, "Reduction of multidrugresistant and drug-susceptible Salmonella in ground beef and freshly harvested beef briskets after exposure to commonly used industry antimicrobial interventions," Journal of Food Protection, vol. 73, no. 7, pp. 1231-1237, 2010.

[33] G. Cebrián, N. Sagarzazu, A. Aertsen, R. Pagán, S. Condón, and P. Mañas, "Role of the alternative sigma factor sigma on Staphylococcus aureus resistance to stresses of relevance to food preservation," Journal of Applied Microbiology, vol. 107, no. 1, pp. 187-196, 2009.

[34] C. J. Potenski, M. Gandhi, and K. R. Matthews, "Exposure of Salmonella enteritidis to chlorine or food preservatives increases susceptibility to antibiotics," FEMS Microbiology Letters, vol. 220, no. 2, pp. 181-186, 2003.

[35] F. Liu and Y. Li, "Storage characteristics and relationships between microbial growth parameters and shelf life of MAP sliced onions," Postharvest Biology and Technology, vol. 40, no. 3, pp. 262-268, 2006.

[36] Y. Hong, W. B. Yoon, L. Huang, and H. Yuk, "Predictive modeling for growth of non- and cold-adapted Listeria monocytogenes on fresh-cut cantaloupe at different storage temperatures," Journal of Food Science, vol. 79, no. 6, pp. 1168-1174, 2014.

[37] K. Lu, Y. Sheen, T. Huang et al., "Effect of temperature on the growth of Staphylococcus aureus in ready-to-eat cooked rice with pork floss," Food Microbiology, vol. 89, article 103374, 2020.

[38] L. Huang, "Growth kinetics of Listeria monocytogenes in broth and beef frankfurters-determination of lag phase duration and exponential growth rate under isothermal conditions," Journal of Food Science, vol. 73, no. 5, pp. E235-E242, 2008.

[39] L. Huang, "Growth kinetics of Escherichia coli O157:H7 in mechanically-tenderized beef," International Journal of Food Microbiology, vol. 140, no. 1, pp. 40-48, 2010.

[40] T. Ross, P. Dalgaard, and S. Tienungoon, "Predictive modelling of the growth and survival of Listeria in fishery products," International Journal of Food Microbiology, vol. 62, no. 3, pp. 231-245, 2000.

[41] M. C. Giffel and M. H. Zwietering, "Validation of predictive models describing the growth of Listeria monocytogenes," International Journal of Food Microbiology, vol. 46, no. 2, pp. 135-149, 1999.

[42] L. Collineau, P. Boerlin, C. A. Carson et al., "Integrating wholegenome sequencing data into quantitative risk assessment of foodborne antimicrobial resistance: a review of opportunities and challenges," Frontiers in Microbiology, vol. 10, pp. 11071107, 2019.

[43] N. Caffrey, J. Invik, C. L. Waldner, D. Ramsay, and S. L. Checkley, "Risk assessments evaluating foodborne antimicrobial resistance in humans: a scoping review," Microbial Risk Analysis, vol. 11, pp. 31-46, 2019. 